as well. The results of inquiries made under. the auspices of United Nations' specialized agencies are in the first instance of a confidential nature and are designed to help the Governments concerned. How ever, many excellent accounts are frequently being composed, which could be most useful to workers in special fields, and to administrators in many countries. Such a report is that under discussion, and it is to be hoped that if the Government of Ghana receives requests for copies of the report it will be willing to assent to its distribution.

Dr. Aylward has dealt systematically with many aspects of food technology and its relation to the provision of adequate diets. He has wisely emphasized inherent economic and social dangers of thoughtless introduction into a developing country of new techniques. Such is the perversity of man that valuable methods of preserving much-needed food may be diverted to less needy ends. Thus one of the most important recent changes in Ghana noted by Dr. Aylward is the introduction of ice-plants which provide refrigeration for the storage of animal products, but refrigeration is now also being used to an appreciable extent for cooling commercially prepared soft drinks. This is not necessarily to be deplored; but administrators must be aware that when they sponsor the introduction of a given technique for one end, it may be used also for less-worthy, and sometimes undesirable, purposes.

Usually modern techniquos lead to the production of foods which are more expensive than the original materials. When the product enables some people to obtain foods necessary for their well-being and which they would not otherwise obtain the cost must be ignored. But very often a new product, especially if it is commercially advertised, is regarded as of particular value and may be purchased at unwarranted expense by those not specially in need of it.
In developing countries this is unfortunate and may be a factor leading to malnutrition among sophisticated urban groups. Any means, therefore, of producing food products cheaply is to be encouraged. Perhaps one of the most significant advances in this connexion has been the use of plasties for food packaging. Not only is this kind of material cheaper than metal containers, but also it may provide a better means of preservation than some alternatives. Dr. Aylward directs attention, for example, to the satisfactory use of plastics in the storage of fish meal produced in Ghana.

Proposals have been made for the introduction into Ghana of 'filled milk' composed of skimmed milk powder, water and coconut oil. This poses a troublesome problem for public health administrators. Though such a milk product may be produced relatively cheaply in some circumstances, thus leading to its widespread use among the poor and needy, there is not yet enough evidence of the effects, especially on infants, of repeated ingestion of coconut oil which contains a high proportion of saturated fatty acids, and also a good deal of lauric acid. It is often the case that new preparations of food such as filled milk are readily accepted by the public before administrators are in a position to control their use should this be necessary.

While it is true that the application of scientific methods in the growth, storage and preparation of foods carries possible hazards, it is of the greatest importance, as Dr. Aylward states, to realize that food technology has developed in order to meet the urgent problems associated with feeding ever-enlarging urban communities; modern food industries are essentially a response to public needs. "And it is precisely for this (as well as other reasons) that the food scientist and technologist has a role to play in Ghana." G. R. WAD SWORTH

\title{
CHOOSING FOREST SPECIES
}

$\mathrm{W}$ ORLD requirements for wood and wood products are steadily increasing, though the forms in which it is being used and the kinds of timber most in demand are constantly changing. World forest resources, which are badly distributed in relation to centres of consumption, are becoming inadequate to meet requirements, and acute shortages are already being felt. At the same time, many natural forest types have relatively low production, and the kinds of wood produced are often not those most in demand.

This is particularly true of vast areas of tropical forest where the luxuriance and variety of the growth make them economically a poor proposition. Many of tho species in them are hard, heavy and difficult to season, and are unsaleable. Even in Europe, the large areas of oak forest, often of low quality, which used to meot demands for fuel and heavy constructional timber are becoming a burdon on the market. If future demands for wood are to be met in the quantities and in the kinds of product required, it will be necessary to improve the productive efficiency of forests all over the world, and to grow more intensively those particular species that will be most in demand. The kind of species most likely to be favoured have recently been discussed by Prof. M. V. Laurie of the University of Oxford (Span, 5, No. $1 ;$ 1962).
It is difficult to estimate what will be wanted half a century or more ahead, but this is what the forester has to try to do when formulating his objects of management and considering what species he ought to be growing. Heavy timbers have largely disappeared from constructional uses. On the other hand, softwoods are still used in large quantities for house building and other structural purposes, and recent developments in laminated construction have provided new outlets for softwood timber in short lengths and of relatively low quality.

Present indications are that softwoods will be in greater demand than hardwoods for most purposes, and that general purpose timbers, which at the same time can be used for core stock or laminated construction and can be chipped or pulped, are most likely to be wanted in large quantities in the future. This trend is already roflected in the large programmes for planting conifors in many parts of the world. Although it may not be difficult to envisage the kind of trees that are likely to be needed to meet future requirements, the question of what can be grown on the sites available is more difficult to answer. Here the limitations of climate, soil and biological agencies are crucial. Different species vary greatly in their tolerances of conditions differing from those of their native habitat; so much so, in fact, that it is impos. sible to say with any degree of certainty whether 
exotic species will succeed or fail purely from a comparison of conditions in their native land with those in the locality of introduction.

As an example, the Monterey pine, Pinus radiata, from a restricted area in California, has been outstandingly successful in New Zealand, many parts of Australia, in South Africa, Spain and Chile, and it even grows well in the highlands of Kenya. Again, the Serbian spruce, Picaea omorika, which grows on limestone mountains in a very restricted area in Yugoslavia, grows remarkably well on acid peats in Scotland. In other cases, the reverse may be true, and many species which have a wide natural range, like the Douglas fir or European larch, have developed local strains which are susceptible to the conditions under which they are grown. The only safe way of selecting a species for introduction is to try it, and all large-scale plantings of exotic trees have been preceded by species trials in arboreta or small trial plots where suitability to the locality is tested, followed by larger plot tests on a more limited range of sites where performance can be estimated.

There are many doubts and risks in introducing an exotic species into a new habitat, and it should always be a principle first to see whether any indigenous species will fulfil the objects in view. The principle that one should not consider introducing an exotic species on a large scale if there is an indigenous species that will meet requirements is generally true. In countries like Britain, however, where the only native timber-yielding conifer, the Scots pine, grows relatively slowly, there is a good case for introducing species that will give higher yields. It is fortunate that some of the conifers from the west coast of North America, Sitka spruce, Douglas fir, western hemlock and lodgepole pine, as well as some from Europe, such as Corsican pine, Norway spruce, European larch and, more remotely, the Japanese larch, have proved so successful in Britain. Trials have shown that many species, particularly those from the eastern parts of North America, suffer so seriously from late-spring frosts in Britain as to be not worth growing. Most species of Eucalyptus are found to be too susceptible to frost to be grown safely in Britain, except in sheltered parts of Devon and Cornwall. Corsican pine, when moved to northern British latitudes, is found to be restricted in the elevation at which it can be grown. Teak does not grow well on very heavy soils or on laterites in the tropies and needs some lime in the soil; it seems to require a definite dry season when it is leafless. No amount of information can enable a species to be accepted as safe for large-scale planting without extensive trials.

It frequently happens that a particular species is so superior in performance to all others tried that there is a tendency to rely on it alone in large plantation programmes. This has occurred, for example, in New Zealand and parts of Australia where Pinus radiata has been planted extensively. So far there has been no serious trouble, but there is always the danger that something may go wrong. It is advisable to have one or more alternative species to fall back on in an emergency.

In South Africa, for example, $P$. radiata, which showed great promise to start with, has more recently suffered severely from a fungal disease which kills the leading shoot. There is now a tendency to prefer $P$. patula, another fast-growing pine, which does not suffer from this defect.

\section{ERADICATION OF MALARIA IN EAST AFRICA}

I the annual report of the East African Council for Medical Research*, the director of the East African Institute of Malaria and Vector-Borme Diseases, Dr. G. Pringle, describes how a draft plan has been prepared for the eradication of malaria from East Africa, based on a combined attack with drugs as well as insecticides. The plan has already received critical examination by a meeting of experts held in Tanga, and further inter-territorial consultations are planned.

In the Taveta-Para area, whore spraying with dieldrin was discontinued early in 1959, a close watch on malaria incidence has been kept. Anopheles gambiae has shown a marked increase in numbers, although house catches have still been less than prespraying densities. The longevity of this vector is still reduced, indicating the presence of some continuing insecticidal effect. $A$. funestus, which was almost certainly eradicated from the area, has not reappeared. Although parasite densities are not back to former levels, there has been a major resurgence of the disease in the swampside villages. Studies of the serum $\gamma$-globulin levels in schoolchildren also indicate that an effective immunity has yet to be acquired.

* East African High Commission. The East African Council for Medical Research-Annual Report, 1960/61. Pp. ii + 16. (Nairobi: Government Printer, 1961.) 28 .
The feeding preference of $A$. gambiae, in areas where man and cattle aro both attacked, has been studied with the view of finding out whether the individual mosquitoes show a consistent tendency to feed on one or other host. Results in one area are still inconclusive, but in another district the presence of normal infection-rates in insects caught feeding on cattle clearly showed that the same mosquitoes had fed at different times on both available hosts. Thus, so far, no evidence has been found of two co-existing strains of $A$. gambiae, differing in their feeding habits, and hence probably in their response to insecticides.

Among potential secondary vectors of malaria, infections have been found in $A$. pharoensis and $A$. squamosus, but none in the more abundant and ubiquitous members of the $A$. coustani group. Agegrouping studies indicate that, in all these species of exophilic mosquitoes, longevity is greatly reduced compared with the main house resting vectors.

A flourishing colony of the coastal salt water form of A. gambiae has been established. Crossing experiments with two strains of fresh water $A$. gambiae have shown that, although occasional fertile offspring are produced, a formidable barrier to gene exchange exists. Thus reproductive isolation of the two groups in Nature seems likely, although proof of this has yet to be obtained in the field. 